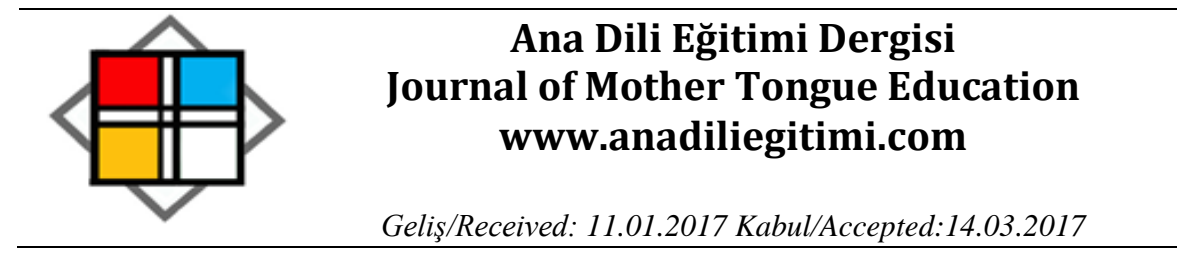

\title{
Türkçe Öğretmeni Adaylarının Farklı Metin Türlerini Dinlerken Aldıkları Notlar Üzerine Bir Değerlendirme
}

\author{
Arif ÇERÇi* \\ Serdar DERMAN ${ }^{* *}$
}

\begin{abstract}
Öz
Bu araştırmanın amacı, Türkçe öğretmeni adaylarının farklı metin türlerini (öyküleyici/öğretici metin) dinlerken aldıkları notları belirlenen tema ve kodlara göre sınıflandırmak ve bu notları sıklıkları/yaygınlıkları bakımından incelemektir. Doküman incelemesi yöntemiyle gerçekleştirilen araştırmanın verileri, 2016-2017 Eğitim Öğretim Yılında Gaziantep Üniversitesi Eğitim Fakültesi Türkçe Öğretmenliği Bölümü üçüncü sınıfta okuyan Türkçe öğretmeni adayı öğrencilerden elde edilmiştir. Toplanan veriler kodlanarak temalara ulaşılmışır. Öyküleyici metin türü için belirlenen temalar; öykünün yapı unsurlarına ilişkin notlar, öyküdeki iletilerle ilgili notlar, metinden yapılan doğrudan alıntılar, öykünün künyesine ilişkin notlardır. Öğretici metin türü için belirlenen temalar ise; öğretici metnin ana düşüncesi ve konusuna ilişkin notlar, metnin yardımcı düşüncelerine ilişkin notlar, metnin künyesi ile ilgili notlar, metinden yapılan doğrudan alıntılardır. Araştırmaya katılan öğrencilerin $\% 84,78$ 'inin öykünün yapı unsurlarına; $\% 19,56$ 'sının öyküdeki ileti-iletilere; $\% 43,47$ 'sinin öykünün künyesine ilişkin not aldığı belirlenmiştir. Öğrencilerin \%41,30'unun metinden doğrudan alıntı yaptığı görülmektedir. Araştırmaya katılan öğrencilerden $\% 40,62$ 'sinin öğretici metnin ana düşüncesi ve konusuna ilişkin; \%82,81'inin öğretici metnin yardımcı düşüncelerine ilişkin; öğrencilerin tamamının öğretici metnin künyesine ilişkin not aldığı belirlenmiştir. Ayrıca metinde yardımcı düşünce, ana düşünce gibi unsurlar doğrudan verilmediği hâlde öğrencilerin \%29,68'inin metnin ana düşüncesi ya da yardımcı düşüncesi olarak doğrudan alıntı yaptığı görülmektedir. Elde edilen bu sonuçlar doğrultusunda dinleme becerisinin gelişiminde metin türlerine uygun not alma tekniklerinin kullanılmasına yönelik önerilerde bulunulmuştur.
\end{abstract}

Anahtar Sözcükler: Dinleme becerisi, Türkçe öğretmen adayları, not alma.

\section{An Evaluation of the Notes Taken By Prospective Turkish Language Teachers While Listening to Different Text Types}

\begin{abstract}
The purpose of this study is to classify the notes taken by prospective Turkish language teachers while listening to different types of texts (narrative/didactic) using predetermined themes and codes and to analyze those notes in terms of frequency and prevalence. The data which were analyzed by using the document analysis method were collected from the third-year prospective Turkish language teachers in the Turkish Language Teacher Education department at Gaziantep University during the 2016-2017 academic year. The data were coded to establish themes. The themes that emerged for narrative texts were: notes concerning the structural aspects of the
\end{abstract}

\footnotetext{
* Yrd. Doç. Dr., Gaziantep Üniversitesi, Eğitim Fakültesi, Sosyal Bilimler ve Türkçe Eğitimi, arifcerci@gmail.com.

** Yrd. Doç. Dr., Gaziantep Üniversitesi, Eğitim Fakültesi, Sosyal Bilimler ve Türkçe Eğitimi, serdarderman@gmail.com
} 


\begin{abstract}
story, notes concerning the messages in the story, direct quotations from the story, and notes concerning the identification tags of the story. As for the didactic text type, the themes that were identified were: notes concerning the main idea and the topic of the didactic text, notes concerning the secondary ideas in the text, notes concerning the identification tags of the didactic text, and direct quotations from the text. It was found that $84,78 \%$ of the participants took notes about the structure of the story; $19,56 \%$ took notes about the message/s in the story, and $43,47 \%$ took notes concerning the identification tags of the story. In addition, $41,30 \%$ quoted directly from the text. $40,62 \%$ of the participants took notes about the main idea and the topic of the didactic text; 82,81 took notes about the secondary ideas in the text, and all of the participants took notes concerning the identification tags of the didactic text. Moreover, although elements like secondary or main idea were not given directly in the texts, $29,68 \%$ of the participants quoted directly from the text as the main idea or the secondary idea in the text. In the light of the results, suggestions were made on the use of appropriate note-taking techniques based on text types in the development of listening skill.
\end{abstract}

Keywords: Listening skill, Prospective Turkish language teachers, Note-taking.

\title{
Giriş
}

Insan günlük hayatta birçok iletişim ortamında bulunmaktadır ve bu ortamlarda iletişim durumuna göre gönderici veya alıcı olabilmektedir. Bilgi edinme sürecinde sözlü, sesli, yazılı ya da görsel kanallarla bireye ulaşan iletiler önemli yer tutmaktadır. Bu iletilerin sayıca fazla olması, bir bölümünün alıcı için anlamsız olması ya da işlevsel olmaması not almayı gerekli kılmaktadır (Özçakmak,2015).

“Not tutma, not düşme, not çıkarma, not yazma" gibi türlü adlar altında belirtilen not alma Türkçe Sözlükte "biri konuşurken onun söylediklerini yazmak, bir şeyi başlıca noktalarını özetleyerek yazmak" (2011: 1779) olarak açıklanmaktadır.

Alan yazında not almaya ilişkin tanımlar incelendiğinde farklı araştırmacılar tarafından farklı tanımlamalar yapıldığı görülmektedir. Bu araştırmacılardan Göğüş'e göre not alma "okunan ya da dinlenilenden, gerekli bir bilginin, beğenilen bir sözün seçilip deftere ya da fişlere yazılması" dır (1978: 284). Uluğ not almayı bilgilerin özetlenerek yazılması olarak açıklamaktadır (1993: 56). Burdurlu'nun tanımı dinleme ve okuma esnasında amaca uygun olarak gerekli hususların yazılması biçimindedir (1975: 244). Oğuzkan not almayı sınıf içi bir eylem olarak değerlendirmekte, anlatılanların ve yapılanların olduğu gibi ya da kısaltılarak yazılması şeklinde açıklamaktadır (1993: 99). Beyreli, Çetindağ ve Celepoğlu not almayı dinleme ve okuma eylemleri sırasında temel bilgilerin yazıyla kaydedilmesi olarak açıklamaktadır. ( 2005: 132). Range (2015)'e göre not alma yazılan kısa mesajlarla unutmayı engellemenin bir yoludur.

Not almaya ilişkin yapılan tanımlar incelendiğinde tanımların daha çok dinleme ve okuma becerileriyle ilişkilendirildiği belirlenmiştir. Ancak birey yalnızca dinlediklerini ve okuduklarını not almaz. Gördükleri ve düşündüklerini de not alabilir (Yörük,1990). Ayrıca not alma eyleminin yazı 
yoluyla gerçekleştirilmesi not almayı yazma becerisiyle de ilişkilendirmeyi gerektirmektedir. Bu özellikleri dikkate alındığında not alma yöntemi Türkçe eğitiminde bütün beceri alanlarıyla ilişkilidir.

Not alma yöntemiyle depolanan bilgiler kalıı hale gelir (Erden, 1991). Not alma, öğrencilerin dinleme sırasında kısa sürede kodlayamadıkları bilgileri harici bir bellek gibi depolayarak gereksinim duyulduğunda öğrenciye yararlanma fırsatı tanır. Notların gözden geçirilmesi ise öğrenilenlerin anlamlandırılmasını olumlu yönde etkilemektedir (Dembo, 1988; Şahin, Aydın ve Sevim, 2011) Not alma ve gözden geçirme süreçleriyle bilgi zihinde iki kez işlenmektedir (Kiewra,1991). Gagne ve Driscol (1988) bu depolama işlevinin bilgilerin geri çağrılmasında da yarar sağladığı görüşündedir.

Dinlerken not almanın derse aktif katılımı sağladığı, öğrenmeleri kalıcı hâle getirdiği, tekrarlama, anlamlandırma ve örgütleme yoluyla zihinsel süreçleri geliştirdiği, akademik başarıyı olumlu yönde etkilediği birçok araştırmacı tarafından kabul edilmektedir (Garner, 1982; Weinstein ve Mayer, 1986 ; Kiewra, 1987; Dembo, 1988; Kiewra, Mayer, Christensen, Kim ve Risch 1991; Erden ve Akman, 1995; Fındıkçı, 1996; Senemoğlu, 2012; Simonet ve Simonet, 2002; Özbay, 2009b).

Not almanın yararlarını not alma sırasında ve sonrasında olmak üzere iki ulamda ele almak mümkündür. Not alma sırasında "1. işitmek, 2. dinlemek, 3. anlamak, 4. analiz etmek, 5.seçmek ve 6. yazmak" (Özbay, 2009a: 122) aşamaları zihinsel bir etkinliğin gerçekleşmesini ve bilgilerin öğrenen için daha anlamlı hâle gelmesini sağlamaktadır. Not alma sonrasında ise öğrenci belirlediği sisteme göre oluşturduğu notlarını gözden geçirerek daha kolay hatırlamakta ve öğrenmenin daha kalıcı olması sağlanmaktadır.

Alan yazında not alma teknikleri; Cornell not alma tekniği, grafiksel not alma tekniği, aynen kaydetme tekniği, paragraf tekniği, ana fikir tekniği (Yıldırım, Doğanay ve Türkoğlu, 2009) gibi birçok biçimde sınıflandırılmış olmakla birlikte ideal bir not alma tekniği yoktur. Çünkü bir iletişim süreci olarak değerlendirilebilecek not alma sürecinde kaynağın, alıcının, iletinin ve kanalın özellikleri farklı not alma tekniklerini gerekli kılabilmektedir (Simonet ve Simonet, 2002). Ancak kullandıkları not alma tekniği ne olursa olsun öğrencilerin öncelikle önemli bilgiyi önemsiz bilgiden ayırt etmeleri gerekmektedir. Çünkü not almanın temelinde önemli bilgileri seçebilmek vardır (Kiewra, 1987). Bu nedenle öğrencilerin farklı türdeki metinleri dinlerken aldıkları notlarda ne tür bilgileri önemli gördüklerinin bilinmesi önem taşımaktadır.

Bu araştırmanın amacı, Türkçe öğretmeni adaylarının farklı metin türlerini dinlerken aldıkları notları; metnin yapı ve içerik özellikleriyle ilişsisi bakımından incelemektir. 


\section{Yöntem}

$\mathrm{Bu}$ çalışma, öğrencilerin dinleme sırasında aldıkları notları çeşitli temalar bakımından sistematik bir şekilde incelemeye yönelik betimsel bir araştırmadır. Çalışmada nitel araştırma yöntemlerinden doküman incelemesi yöntemi kullanılmıştır. "Doküman incelemesi, araştırılması hedeflenen olgu ve olgular hakkında bilgi içeren, yazılı, görsel materyallerin analizini kapsar. Dokümanlar nitel araştırmalarda etkili bir şekilde kullanılması gereken bilgi kaynaklarıdır." (Yıldırım ve Şimşek, 2008: 187-188).

\section{Verilerin Toplanması}

Bu araştırmanın verileri, 2016-2017 Eğitim Öğretim Yılında Gaziantep Üniversitesi Eğitim Fakültesi Türkçe Öğretmenliği Bölümü üçüncü sınıfta okuyan Türkçe öğretmeni adayı öğrencilerden elde edilmiştir. Katılımcılar kolaylık örneklemi yoluyla belirlenmiştir. Kolaylık örnekleminin seçiminde coğrafi yakınlık, kolay erişilebilirlik ve zaman faktörleri etkili olmuştur (Dörnyei, 2007). 2016-2017 Eğitim-Öğretim Yılı güz döneminde okutulan "Anlama Teknikleri II: Dinleme Eğitimi” dersinin yürütücüleri aynı zamanda bu çalışmanın araştırmacılarıdır. Araştırmacılar öğretmen adaylarının farklı metin türlerini dinlerken önemli bilgiyi önemsiz bilgiden ayırt etme durumunu belirlemek için öğrencilere farklı metin türlerini dinletmiş ve metinlerle ilgili not almalarını istemiştir. Bu dinleme işlemi araştırmacıların metinleri sesli okumaları ile gerçekleşmiştir. Öğretmen adaylarından not alırken kısaltma kullanmamaları istenmiş ve dinleme sonrasında notlarını gözden geçirmeleri için beş dakika süre verilmiştir. Uygulama iki haftalık bir süreçte gerçekleştirilmiştir. Uygulamanın birinci haftasında öğrencilere Türk Edebiyatı 9. Sınıf Ders Kitabından (Derman ve Ateş:2015) seçilen "Akrep" adlı öykü dinletilmiş ve not almaları istenmiştir. Bu çalışmaya 46 öğrenci katılmıştır. Uygulamanın ikinci haftasında ise aynı kitaptan seçilen "Yavuz Sultan Selim" adlı öğretici metin dinletilmiş ve çalışmaya 64 öğrenci katılmıştır. Uygulamaların sonunda öğretmen adaylarının dinledikleri metinlere ilişkin aldıkları notlar araştırmanın verilerini oluşturmuştur.

\section{Verilerin Kodlanması ve Çözümlenmesi}

Öğretmen adaylarının dinleme sırasında tuttukları notlardan elde edilen veriler içerik analizi yöntemi kullanılarak çözümlenmiştir. "Araştırmada toplanan verileri açıklayabilecek kavramlara ve ilişkilere ulaşmak amaçlandığından içerik analizi yöntemi kullanılmıştır. İçerik analizi yazılı, sözlü bir metni veya sembolü analiz edip rakamlara dönüştürüp bu rakamların üzerinden yoruma gitmek, diğer bir deyişle rakamları tekrar söze dönüştürmek olarak tanımlanabilir."(Şahin, 2010: 189).

Toplanan notlar araştırmacılar tarafından okunmuş ve notlarda yer alan veriler aşağıda belirlenen temalar ve temaların alt boyutlarına göre kodlanmıştır: 
Tablo 1. Öyküleyici metne ilişkin temalar ve alt boyutları

\begin{tabular}{lccc}
\hline \multicolumn{1}{c}{ Temalar } & Alt Boyutlar \\
\hline Öykünün yapı unsurlarına ilişkin notlar & Olay & Kişiler Yer Zaman & Anlatıcı \\
Öyküdeki iletilerle ilgili notlar & Metindeki iletiye ilişkin her ifade \\
Öykünün Künyesine ilişkin Notlar & Yazara ilişkin bilgiler & Metnin başlığı \\
Metinden yapılan doğrudan alıntılar & \multicolumn{2}{c}{ Metinden yapılan doğrudan alıntılar } \\
\hline
\end{tabular}

\section{Verilerin Kodlanmasına İlişkin Örnekler:}

"istanbul modern bir şehir" Ö:13 (Yer)

“Ebu Akrep" Ö:19 (Şahıs)

“ Uzaktakiler için İstanbul'un kötü yeri yoktur.” Ö: 24 (Doğrudan alıntı)

“Refik Halit Karay” Ö:38 (Künye)

Tablo 2. Öğretici metne ilişkin temalar ve alt boyutları

\begin{tabular}{lll}
\hline \multicolumn{1}{c}{ Temalar } & \multicolumn{2}{c}{ Alt Boyutlar } \\
\hline $\begin{array}{l}\text { Öğretici metnin ana düşüncesi ve konusuna } \\
\text { ilişskin Notlar }\end{array}$ & $\begin{array}{l}\text { Ana düşünceye ilişkin } \\
\text { notlar }\end{array}$ & $\begin{array}{l}\text { Metnin konusuna ilişkin } \\
\text { notlar }\end{array}$ \\
$\begin{array}{l}\text { Öğretici Metnin Yardımcı düşüncelerine iliş̧in } \\
\text { Notlar }\end{array}$ & Yardımcı düşüncelere ilişkin notlar \\
Öğretici Metnin Künyesi ile ilgili Notlar & Yazara ilişkin bilgiler & Metnin başlığı \\
Metinden yapılan doğrudan alıntılar & Metinden yapılan doğrudan alıntılar \\
\hline
\end{tabular}

\section{Verilerin Kodlanmasına İlişkin Örnekler:}

“Yavuz Sultan Selim"Ö: 44 (Künye)

"Hayatımda dedemin kucağında olan saadeti duymadım." Ö: 39 (Doğrudan alıntı)

"Tarihin akışını değiştiren bir cihangirdir." Ö:53 (Metnin ana düşüncesi ve konusuna ilişkin notlar)

“Bilime sanata büyük önem vermiştir." Ö: 62 (Metnin yardımcı düşüncelerine ilişkin notlar)

Araştırmadaki kodlama araştırmacılar tarafından birbirinden bağımsız olarak yapılmıştır. íki kodlama karşılaştırılmış ve güvenirlik (güvenirlik = görüş birliği / görüş birliği + görüş ayrılığı x 100) (Miles ve Huberman, 1994:64) formülü ile hesaplanmış, iki kodlama arasındaki uyum \%92 olarak bulunmuştur. Daha sonra bu kodlar özellikleri bakımından sınıflandırılarak temalara- kategorilere ulaşılmıştır. Elde edilen temalar sıklık ve yaygınlık bakımından oransal olarak tablolaştırımıştır. 


\section{Bulgular ve Yorum}

Bu bölümde araştırmada elde edilen verilerden hareketle bulgu ve yorumlara yer verilmiştir.

Öykü Türünde Alınan Notların Temalar Bakımından Sıklık ve Yaygınlığına Dair Bulgu ve Yorumlar

Tablo 3. Öykü türünde alınan notların temalar bakımından sıklık ve yaygınlığı

\begin{tabular}{lcccc}
\hline & \multicolumn{2}{c}{ Yaygınlık } & & Sıklık \\
\cline { 2 - 5 } Tema N=46 & $\mathrm{f}$ & $\%$ & $\mathrm{f}$ & $\%$ \\
Öykünün yapı unsurlarına ilişkin notlar & 39 & $\% 84,78$ & 81 & $\% 46,55$ \\
Öyküdeki iletilerle ilgili notlar & 9 & $\% 19,56$ & 9 & $\% 5,19$ \\
Öykünün Künyesine ilişkin Notlar & 20 & $\% 43,47$ & 25 & $\% 14,36$ \\
Metinden yapılan doğrudan alıntılar & 19 & $\% 41,30$ & 59 & $\% 33,90$ \\
\hline
\end{tabular}

Tablo 3. incelendiğinde en fazla sıklık gösteren temanın 81 tekrarla $(\% 46,55)$ öykünün yapı unsurlarına ilişkin notlar olduğu görülmektedir. Bu temaya ilişkin olarak 39 öğrenci $(\% 84,78)$ tarafından not alınmıştır. Bu temayı sıklık bakımından 59 tekrarla $(\% 33,90)$ öyküden yapılan doğrudan alıntılar ve 25 tekrarla $(\% 14,36)$ öykünün künyesine ilişkin notlar teması takip etmektedir. Sıklık bakımından en düşük değerler ise 9 tekrarla $(\% 5,19)$ öyküdeki iletilerle ilgili notlara aittir. Bu durum sıklık bakımından değerlendirildiğinde öğretmen adaylarının en fazla önem verdikleri bilgilerin metnin yapı unsurlarıyla ilgili olduğu söylenebilir.

Temalar yaygınlık bakımından incelendiğinde, 39 öğrenciyle $(\% 84,78)$ öykünün yapı unsurlarına ilişkin notlar teması en yüksek değere sahiptir. Bunu 20 öğrenciyle $(\% 43,47)$ öykünün künyesine ilişkin notlar takip etmektedir. Öyküden 19 öğrencinin $(\% 41,30)$ doğrudan alıntılar yaptığı belirlenmiştir. Yaygınlık bakımından son sırada 9 öğrenciyle $(\% 19,56)$ öyküdeki iletilerle ilgili notlar teması yer almaktadır. Bu durum yaygınlık bakımından değerlendirildiğinde öğretmen adaylarının en fazla önem verdikleri bilgilerin metnin yapı unsurlarıyla ilgili olduğu söylenebilir. Sıklık ve yaygınlık değerleri birlikte değerlendirildiğinde öğretmen adaylarının metnin yapı unsurlarını belirlemede daha başarılı oldukları söylenebilir.

Öğretici Metin Türünde Alınan Notların Temalar Bakımından Sıklık ve Yaygınlığı Dair Bulgu ve Yorumlar

Tablo 4. Öğretici metin türünde alınan notların temalar bakımından sıklık ve yaygınlığı

\begin{tabular}{|c|c|c|c|c|}
\hline \multirow{2}{*}{ Tema $\mathrm{N}=64$} & \multicolumn{2}{|c|}{ Yaygınlık } & \multicolumn{2}{|c|}{ Sıklık } \\
\hline & $f$ & $\%$ & $f$ & $\%$ \\
\hline
\end{tabular}




\begin{tabular}{lcccc}
\hline $\begin{array}{l}\text { Öğretici metnin ana düşüncesi ve } \\
\text { konusuna ilişkin notlar }\end{array}$ & 26 & $\% 40,62$ & 44 & $\% 4,84$ \\
$\begin{array}{l}\text { Öğretici metnin yardımcı düşüncelerine } \\
\text { ilişkin notlar }\end{array}$ & 53 & $\% 82,81$ & 53 & $\% 5,85$ \\
$\begin{array}{l}\text { Öğretici metnin künyesi ile ilgili notlar } \\
\text { Metinden yapılan doğrudan alıntılar }\end{array}$ & 64 & $\% 100$ & 790 & $\% 87$ \\
\hline
\end{tabular}

Tablo 4. incelendiğinde sıklık değeri bakımından öğretici metnin künyesine ilişkin notların 790 tekrarla (\% 87) en yüksek değere sahip olduğu görülmektedir. Bunu 53 tekrarla $(\% 5,85)$ öğretici metnin yardımcı düşüncelerine ilişkin notlar izlemektedir. 44 tekrarla (\% 4, 84) ana düşünce ve konuya ilişkin notlardan sonra 21 tekrarla $(\% 2,31)$ metinden yapılan doğrudan alıntılar gelmektedir. Bu durum öğretmen adaylarının metnin künyesine ilişkin bilgileri metne ilişkin diğer bilgilerden daha önemli gördükleri şeklinde yorumlanabilir.

Tablo 4. yaygınlık bakımından incelendiğinde öğrencilerin tamamının öğretici metnin künyesine ilişkin not aldığı görülmektedir. Bu temayı 53 öğrenciyle $(\% 82,81)$ metnin yardımcı düşüncelerine ilişkin notlar izlemektedir. 26 öğrenci $(\% 40,62)$ metnin ana düşüncesi ve konusuna ilişkin notlar almıştır. En az yaygınlık gösteren ise 19 öğrenciyle $(\% 29,68)$ metinden yapılan doğrudan alıntılardır. Bu durum öğretmen adaylarının tamamının metnin künyesine ilişkin bilgileri diğer bilgilerden daha önemli gördükleri şeklinde yorumlanabilir.

\section{Sonuç ve Tartışma}

Araştırmanın temalarından hareketle öyküleyici ve öğretici metin türüyle ilgili elde edilen bulgulara ait sonuçlar şöyledir:

1. Araştırmaya katılan öğrencilerin $\% 84,78$ 'i öykünün yapı unsurlarına; $\% 19,56$ 'sı öyküdeki ileti-iletilere; \%43,47'si öykünün künyesine ilişkin not aldığı belirlenmiştir. Öğrencilerden $\% 41,30$ ’unun metinden doğrudan alıntı yaptığı görülmektedir.

2. Araştırmaya katılan öğrencilerin $\% 40,62$ 'si öğretici metnin ana düşüncesi ve konusuna ilişkin; \%82,81'i öğretici metnin yardımcı düşüncelerine ilişkin; öğrencilerin tamamının öğretici metnin künyesine ilişkin not aldığı belirlenmiştir. Ayrıca metinde yardımcı düşünce, ana düşünce gibi unsurlar doğrudan verilmediği hâlde öğrencilerin $\% 29,68$ 'i metinden doğrudan alıntı yaptığı görülmektedir.

Ulaşılan sonuçlara göre öğretmen adaylarının öğretici metin türünde metnin ana düşüncesi ve konusunu belirlemeye ilişkin aldıkları notların yetersiz olduğu görülmektedir. Bu sonuç Susar ve Akkaya (2009)'nın üniversite öğrencilerinin özetleme becerileri konusunda yaptıkları çalışmanın 
sonucuyla benzerlik göstermektedir. Susar ve Akkaya çalışmanın sonucunda, öğrencilerin özetlerinde ana düşünceden uzaklaştıkları, ana düşünceyi yüzeysel bir şekilde özetledikleri ve ana düşünce ile yardımcı düşünceleri ilişkilendirme konusunda yetersiz oldukları bulgularına ulaşmıştır. Kintsch (1990) yaptığı çalışmada ise üniversite öğrencilerinin çıkarımları özetleri şekillendirmede kullanabildikleri; bilgileri metnin ana düşüncesini belirlemek için düzenleyebildikleri sonucuna ulaşmıştır.

Öğretmen adaylarının metnin iletisine ilişkin aldıkları notlara bakıldığında bu notların da nicel anlamda yetersiz olduğu görülmektedir. Bu sonuç Taylor (1986) tarafından gerçekleştirilen çalışmanın sonuçlarıyla benzerlik göstermektedir. Taylor çalışmasında öğrencilerin okudukları metnin iletisini belirlemede yetersiz oldukları sonucuna ulaşmıştır. Ulaşılan bu sonuçlar metinlerin ana düşüncesini ve iletisini belirlemede yetersiz olan öğrencilerin metinden doğrudan alıntı yapmaya yöneldiklerini göstermektedir.

Elde edilen sonuçlar bir bütün olarak değerlendirildiğinde; Dilidüzgün (2013)'ün yaptığı çalışmada öğretmenlere uyguladığı anketten elde edilen sonuçlar ile örtüşmektedir. Dilidüzgün çalışmasında sınıf içi etkinliklerde öğrencilere sadece metnin ana düşüncesi, konusu, olay ve kahramanların sorulduğunu, dolayısıyla metnin içeriksel ve üst yapısal özelliklerinin göz ardı edildiğini ifade etmektedir. Buradan hareketle öğrencilerin metnin konusu, iletisi, ana düşüncesi, yardımcı düşünceleri ve olay örgüsü gibi unsurlar arasındaki ilişkileri belirlemekte ve ifade etmekte güçlük yaşadıkları söylenebilir.

\section{Öneriler}

Araştırmanın bu bölümünde, elde edilen sonuçlardan hareketle aşağıdaki önerilere yer verilmiştir.

1. Not alma yöntemine dinleme etkinliklerinin yanı sıra, okuma ve yazma etkinliklerinde de yer verilmelidir.

2. Öğretmenler metin türü ve yapısına göre not alma çalışmalarını öğrencilerle birlikte yapmalı, kendileri aldıkları notlarla öğrencilere örnek olmalı, böylece öğrencilerin not alma becerilerinin gelişmesine katkıda bulunmalıdır.

3. Öğretmen adaylarına lisans düzeyinde sadece dinleme eğitimi derslerinde değil aynı zamanda okuma ve yazma eğitimi derslerinde de not alma tekniklerine yönelik uygulamalı çalışmalar yaptırılmalıdır.

\section{Kaynaklar}

Beyreli, L., Çetindağ, Z. ve Celepoğlu, A. (2005). Yazılı ve sözlü anlatım. Ankara: Pegem A Yayıncılık. 
Burdurlu, I. Z. (1975). Türkçe kompozisyon (I. Cilt; İzmir Eğitim Enstitüsü Ders Kitapları). İzmir: Karınca Matbaacılık.

Dembo, M. H. (1988) Applying educational psychology in the classroom. (3. Baskı), Newyork: Longman.

Derman, S. ve Ateş, M. (2015). Ortaöğretim Türk edebiyatı 9. sınıf ders kitabı. M. Oktay (Ed.) Ankara: Ekoyay.

Dilidüzgün, Ş. (2013). Ortaokul Türkçe derslerinde okumadan özet yazmaya. Ankara Üniversitesi Eğitim Bilimleri Fakültesi Dergisi, 46(2), 47-68.

Dörnyei, Z. (2007). Research methods in applied linguistics: Quantitative, qualitative, and mixed methodologies. Oxford University Press.

Erden, M. ve Akman, Y. (1995). Eğitim psikolojisi: gelişim, öğrenme, öğretme. Ankara: Arkadaş Yayınevi.

Erden, M. (1991). Öğrenme sürecinde not tutmanın rolü. Yaşadıkça Eğitim, 15, 15-17.

Fındıkçı, İ. (1996). Not alır mısınız? Yaşadıkça Eğitim, 48, 18-19.

Gagne, R. M.\& Driscoll, M. P. (1988). Essentials of learning for Instruction. (2. Baskı). New Jersey: Prentice Hall, Englewood Cliffs.

Garner, R. (1982). Efficient text summarization: Costs and benefits. The Journal of Educational Research, 75(5), 275-279.

Göğüş, B. (1978). Orta dereceli okullarımızda Türkçe ve yazın eğitimi. Ankara: Kadıoğlu Matbaacılık.

Kiewra, K. A. (1987). Notetaking and review: The research and its implications. Instructional Science, 16(3), 233249.

Kiewra, K. A. (1991). Aids to lecture learning. Educational Psychologist, 26(1), 37-53.

Kiewra, K. A., Mayer, R. E., Christensen, M., Kim, S. I. \& Risch, N. (1991). Effects of repetition on recall and notetaking: Strategies for learning from lectures. Journal of Educational Psychology, 83(1), 120-123.

Kintsch, E. (1990). Macroprocesses and microprocesses in the development of summarization skill. Cognition and instruction, 7(3), 161-195.

Miles, M. H., \& Huberman, M. AM (1994). Qualitative data analysis. An expanded sourcebook 2nd edition. London: Sage Publications.

Oğuzkan, F. (1993) Eğitim terimleri sözlüğü. (3. Basım), Ankara: Emel Matbaacılık.

Özbay, M. (2009a). Anlama teknikleri II: Dinleme eğitimi. Ankara: Öncü Yayınevi.

Özbay, M. (2009b). Anlama teknikleri I: Okuma eğitimi. Ankara: Öncü Yayınevi.

Özçakmak, H. (2015) Türkçe öğretmeni adaylarının not alarak dinlemede özetleme stratejilerini kullanma becerileri. Yayınlanmamış doktora tezi, Gazi Üniversitesi.

Range, E. (2015). Take note! Taking and organizing notes. Michigan: Cherry Lake Publishing.

Senemoğlu, N. (2012). Gelişim öğrenme ve öğretim: Kuramdan uygulamaya. (21.Baskı) Ankara: Spot Matbaacılık.

Simonet, R. ve Simonet, J. (2002). Not alma teknikleri (3. Baskı, Çev., P. Kurt). İstanbul: Arion Yayınevi.

Susar, F. ve Akkaya, N. (2009). University students for using the summarizing strategies. Procedia Social and Behavioral Sciences, 1(1), 2496-2499.

Şahin, A., Aydın, G., ve Sevim, O. (2015). Cornell not alma tekniğinin dinlenilen metni anlamaya ve kalıcılığa etkisi. Dumlupınar Üniversitesi Sosyal Bilimler Dergisi, (29),29-36.

Şahin, Ç.( 2010). Verilerin analizi. R.Y. Kıncal, (Ed.) Bilimsel araştırma yöntemleri içinde (181-215). Ankara:Nobel Yayın Dağıtım. 
Türkçe Öğretmeni Adaylarının Farklı Metin Türlerini Dinlerken Aldıkları Notlar Üzerine Bir Değerlendirme

Taylor, K. K. (1986). Summary writing by young children. Reading Research Quarterly, 21(2), 193-208.

TDK. (2011). Türkçe sözlük. Ankara: TDK Yayınları.

Uluğ, F. (1993). Okulda başarı. (3. Baskı), İstanbul: Remzi Kitabevi.

Weinstein, C. E. Ve Mayer, R. E. (1986). The teaching of learning strategies. (Editör: M. C.Wittrock), İçinde handbook of research on teaching. (3. Baskı), Newyork: Macmillan Company. 315-327.

Yıldııım, A. Şimşek, H. (2008). Sosyal bilimlerde nitel araştırma yöntemleri (7. Baskı). Ankara: Seçkin Yayıncılık.

Yıldırım, A., Doğanay, A. ve Türkoğlu, A. (2009). Okulda başarı için ders çalışma ve öğrenme yöntemleri. (2. basım). Ankara: Seçkin Yayıncılık.

Yörük, Y. (1990). Güzel konuşma-yazma kılavuzu. (22. Baskı) Ankara: Eğitim Yayınevi. 